\title{
First case report of vancomycin-intermediate sequence type 72 Staphylococcus aureus with nonsusceptibility to daptomycin
}

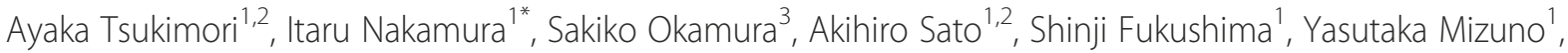 \\ Tetsuo Yamaguchi ${ }^{4}$ and Tetsuya Matsumoto ${ }^{2}$
}

\begin{abstract}
Background: Sequence type 72 methicillin-resistant Staphylococcus aureus (MRSA) SCCmec type IV (ST72-MRSA-IV) is the most common community-acquired MRSA clone in Korea. Resistance to daptomycin or vancomycin among community-acquired MRSA clones is not well described in the literature. We herein report the first case of vancomycin-intermediate, daptomycin-nonsusceptible ST72-MRSA-IV.

Case presentation: A 45-year-old Japanese man underwent aortic arch prosthesis implantation for treatment of a dissecting aortic aneurysm. Fourteen months later, he developed a prosthetic graft infection of the aortic arch and an anterior mediastinal abscess caused by ST72-MRSA-IV. First-line treatment with vancomycin and rifampicin failed, and daptomycin was thus administered. After several days, the treatment was changed to linezolid because of the re-emergence of fever. The patient's condition resolved and no recurrence or other problems were seen for 1 year post-treatment. The infectious agent was definitively identified as vancomycin-intermediate, daptomycin-nonsusceptible, rifampicin-resistant ST72-MRSA-IV based on culture results and minimum inhibitory concentration testing.

Conclusion: This case report illustrates the importance of fully understanding the changing epidemiology of infectious agents and the risk factors for the development of antibiotic resistance. Such information will help to minimize the emergence and spread of antibiotic-resistant strains. This report concerns one particular bacterial strain; however, the basic concepts involved in this case translate to all infectious disease fields.
\end{abstract}

Keywords: MRSA, Daptomycin, Sequence type 72-MRSA-SCCmec type IV (ST72-MRSA-IV), Daptomycin nonsusceptibility, Vancomycin-intermediate resistance, Rifampicin resistance, High-dose daptomycin

\section{Background}

Community-acquired methicillin-resistant Staphylococcus aureus (CA-MRSA) was first reported in 1981 in patients with MRSA infections without general healthcare-associated risk factors. The incidence of CA-MRSA infection has continually increased since the mid-1990s [1]. The features of CA-MRSA strains differ from those of healthcare-associated MRSA (HA-MRSA) strains. Reported differences between infections with these two strains include genetic traits, clinical features, patient groups, infection routes, recommended treatments and manage-

\footnotetext{
*Correspondence: task300@tokyo-med.ac.jp

${ }^{1}$ Department of Infection Control and Prevention, Tokyo Medical University Hospital, 6-7-1 Nishishinjuku, Shinjuku-ku, Tokyo 160-0023, Japan

Full list of author information is available at the end of the article
}

ment, prevention procedures, and antimicrobial susceptibility patterns [2]. In recent years, however, these strains have been frequently observed in healthcare settings and have been shown to cause both community-onset healthcare-associated infections and nosocomial infections $[1,3]$.

CA-MRSA clones vary among geographic settings. Sequence type 8 (ST8)-staphylococcal cassette chromosome mec (SCCmec) type IV (ST8-MRSA-IV, known as USA300) is the most common and epidemic CA-MRSA clone in North America [4]. The most predominant CA-MRSA clones in Asian countries include ST59MRSA-IV in Taiwan, Hong Kong, Vietnam, and Sri Lanka; ST30-MRSA-IV in the Philippines; and ST72MRSA-IV in Korea. Clinical strains of ST72-MRSA-IV are mostly limited to Korea and lack Panton-Valentine

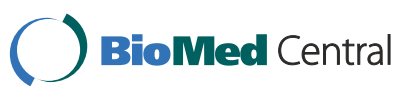

(c) 2014 Tsukimori et al.; licensee BioMed Central Ltd. This is an Open Access article distributed under the terms of the Creative Commons Attribution License (http://creativecommons.org/licenses/by/4.0), which permits unrestricted use, distribution, and reproduction in any medium, provided the original work is properly credited. The Creative Commons Public Domain Dedication waiver (http://creativecommons.org/publicdomain/zero/1.0/) applies to the data made available in this article, unless otherwise stated. 
leukocidin (PVL) genes. ST72-MRSA-IV isolates usually have very low resistance to most non- $\beta$-lactam agents, which is a typical characteristic of CA-MRSA isolates containing SCCmec type IV elements [5]. Multidrug resistance in ST72-MRSA-IV isolates has rarely been reported [6,7]. ST72-MRSA-IV strains, like other CA-MRSA strains, commonly cause skin and soft tissue infections or pneumonia and have sometimes been associated with serious or fatal diseases such as severe sepsis, septic shock, and surgical site infection [8].

Daptomycin was first approved in 2003 for the treatment of complicated Gram-positive skin and skin structure infections. It is a novel lipopeptide antibiotic with a unique mechanism of action against Gram-positive bacteria, binding to bacterial membranes and causing rapid depolarization of the membrane potential [9]. Because daptomycin was confirmed to be effective against strains that were resistant to existing antibiotics, its clinical application has been increasing as the first-line therapy for bacteremia, surgical site infection, and right-sided infective endocarditis [10]. With the exception of USA300, resistance to daptomycin or vancomycin among CAMRSA clones has not been well described $[11,12]$. The first case of an ST72-MRSA-IV strain in Asia demonstrating vancomycin-intermediate resistance was reported in 2012 by Chung et al. in Korea [13]. To our knowledge, the present case is the first report of an ST72-MRSA-IV strain with daptomycin nonsusceptibility and vancomycinintermediate resistance.

\section{Case presentation}

\section{Clinical presentation}

A 45-year-old Japanese man presented to the emergency department with the main complaints of fever and disturbance of consciousness (Glasgow Coma Score of E3V4M6). He had a previous medical history of dissecting aortic aneurysm (Stanford type A), for which he underwent transverse aortic arch replacement 14 months before admission. He had no history of travelling abroad or having his skin pierced. He had previously been treated with vancomycin at $3 \mathrm{~g} /$ day ( $1 \mathrm{~g}$ intravenously [IV] three times a day [TID]) and rifampicin at $600 \mathrm{mg} /$ day $(300 \mathrm{mg}$ orally [PO] twice a day [BID]) for 2 days before being transferred to our hospital.

The patient's condition was diagnosed as an anterior mediastinal abscess and hemorrhagic cerebral infarction associated with a prosthetic graft infection of the aortic arch. Surgical intervention to remove the infected graft, which required anticoagulant therapy during cardiopulmonary bypass, was not possible because of intracerebral hemorrhage. Initial treatment for the prosthetic graft infection was started with vancomycin at $3 \mathrm{~g}$ /day ( $1 \mathrm{~g}$ IV TID) and cefazolin at $6 \mathrm{~g} /$ day ( $2 \mathrm{~g}$ IV TID). On the second hospital day, drainage and continuous irrigation were started for treatment of the anterior mediastinal abscess. Because the results of the blood culture performed 2 days before admission revealed an MRSA infection, the treatment was switched to vancomycin at $3 \mathrm{~g} /$ day ( $1 \mathrm{~g}$ IV TID) and rifampicin at $600 \mathrm{mg} /$ day (300 $\mathrm{mg}$ PO BID); this treatment was continued for 9 days. The isolates from the blood and anterior mediastinal cultures performed on the day of admission also indicated MRSA infection. The vancomycin serum trough levels remained at 9.8-12.2 $\mu \mathrm{g} / \mathrm{ml}$ during vancomycin treatment. The vancomycin minimum inhibitory concentration (MIC) of the MRSA strain isolated from the pus in the abscess was $2 \mu \mathrm{g} / \mathrm{ml}$, and this strain was also susceptible to most non- $\beta$-lactam agents except gentamicin (Table 1 ). The blood culture became negative for MRSA during the course of vancomycin and rifampicin therapy. However, the patient became feverish again on the 10th hospital day, and the treatment was switched to IV daptomycin at $6 \mathrm{mg} / \mathrm{kg} /$ day and rifampicin. On the 40th day, after the patient had remained in a stable condition for several days with daptomycin and rifampicin treatment, his fever returned and the blood culture became positive again for MRSA. Therefore, we suspected nonsusceptibility to daptomycin. Daptomycin was discontinued and treatment with linezolid was initiated at $1200 \mathrm{mg} /$ day $(600 \mathrm{mg}$ IV BID). Reconstruction of the acute aortic dissection was carried out on the 61st day because the chest computed tomography scan performed during therapy showed persistence of the anterior mediastinal abscess and gallium scintigraphy showed persistence of prosthetic graft-associated inflammation. The infected prosthetic graft was completely removed and replaced. After the surgery, antimicrobial treatment was switched to linezolid at $1200 \mathrm{mg} /$ day (600 mg PO BID) and clindamycin

Table 1 Susceptibility of MRSA to various antimicrobial agents analyzed by clinical laboratory testing

\begin{tabular}{|c|c|c|c|c|c|}
\hline \multirow{2}{*}{$\begin{array}{l}\text { Antimicrobial } \\
\text { agent }\end{array}$} & \multicolumn{5}{|c|}{ MIC $(\mu \mathrm{g} / \mathrm{ml})$ [interpretation] } \\
\hline & Isolate 1 & Isolate 1' & Isolate 2 & Isolate 3 & Isolate 4 \\
\hline Oxacillin & $>4[\mathrm{R}]$ & $>4[R]$ & $>4[R]$ & $>4[\mathrm{R}]$ & $>4[\mathrm{R}]$ \\
\hline Gentamicin & $8[R]$ & $>8[R]$ & $8[R]$ & $>8[\mathrm{R}]$ & $>8[\mathrm{R}]$ \\
\hline Erythromycin & $<0.25[S]$ & $<0.25[S]$ & $<0.25[\mathrm{~S}]$ & $<0.25[S]$ & $<0.25[\mathrm{~S}]$ \\
\hline Clindamycin & $<0.5[S]$ & $<0.5[S]$ & $<0.5[S]$ & $<0.5[S]$ & $<0.5[S]$ \\
\hline Minocycline & $<2[\mathrm{~S}]$ & $<2[\mathrm{~S}]$ & $<2[\mathrm{~S}]$ & $<2[\mathrm{~S}]$ & $<2[\mathrm{~S}]$ \\
\hline Teicoplanin & $<2[\mathrm{~S}]$ & $<2[\mathrm{~S}]$ & $<2[\mathrm{~S}]$ & $4[S]$ & $4[S]$ \\
\hline Vancomycin & $1[S]$ & $2[S]$ & $1[S]$ & $2[S]$ & $4[1]$ \\
\hline Levofloxacin & $<0.5[S]$ & $<0.5[\mathrm{~S}]$ & $<0.5[\mathrm{~S}]$ & $<0.5[\mathrm{~S}]$ & $<0.5[S]$ \\
\hline Rifampicin & $<1[S]$ & $<1[S]$ & $>2[R]$ & $>2[R]$ & $>2[\mathrm{R}]$ \\
\hline
\end{tabular}

Susceptibilities to the agents in Table 1 were evaluated by broth microdilution (MicroScan; Siemens, Tokyo, Japan).

Isolate 1: blood culture on the first hospital day; Isolate1': pus from the abscess on the first hospital day; Isolate 2: pus from the abscess on the sixth hospital day; Isolate 3: blood culture on the 40th hospital day; Isolate 4: pus from the abscess on the 55th hospital day. S: Susceptible; I: Intermediate; R: Resistant. 
at $1800 \mathrm{mg} /$ day (600 mg PO TID). The patient's condition subsequently improved, and recurrence was not observed for 12 months of follow-up. The time course of his body temperature variations and antibiotic treatment regimen are shown in Figure 1.

\section{Methods and results}

Antimicrobial susceptibility testing was performed according to the Clinical and Laboratory Standards Institute (CLSI) guidelines (Tables 1 and 2). Rifampicin susceptibility testing, not routinely included, was performed after the treatment and revealed resistance at an MIC of $>2 \mu \mathrm{g} / \mathrm{ml}$ from Isolate 2 in the course of vancomycin and rifampicin dosing (Table 1). The MRSA isolate from the pus in the abscess on the 55th hospital day (Isolate 4) demonstrated a vancomycin MIC of $4 \mu \mathrm{g} / \mathrm{ml}$, indicating vancomycinintermediate $S$. aureus (VISA) (Table 1). The daptomycin MICs of the MRSA isolates obtained from the blood and anterior mediastinal abscess cultures were evaluated by the broth microdilution method, using MicroScan (Siemens, Tokyo, Japan) and frozen plate (Eiken Chemical Co., Ltd., Tokyo, Japan), and Etest ${ }^{\circ}$ (bioMérieux, Marcy-l'Étoile, France). The MRSA isolates showed susceptibility to daptomycin at the time of admission, with MICs of $\leq 0.5 \mu \mathrm{g} / \mathrm{ml}, 0.5$, and $0.125 \mu \mathrm{g} / \mathrm{ml}$ upon analysis by MicroScan, frozen plate, and Etest ${ }^{\circ}$, respectively. Over time, however, these MICs increased to $>1,1.5$, and $1.5 \mu \mathrm{g} / \mathrm{ml}$, respectively, indicating daptomycin nonsusceptibility (Table 2). The interpretations of the MIC results (susceptible, intermediate, nonsusceptible, or resistant) were determined according to the CLSI guidelines. MRSA isolates with daptomycin MICs of $>1 \mu \mathrm{g} / \mathrm{ml}$, vancomycin MICs of 4 to $8 \mu \mathrm{g} / \mathrm{ml}$, and rifampicin MICs of $>2 \mu \mathrm{g} / \mathrm{ml}$ were defined as daptomycin nonsusceptible, vancomycin-intermediate resistant, and rifampicin resistant, respectively.

Pulsed-field gel electrophoresis was performed using a contour-clamped homogeneous electric field dynamic regulation III system (CHEF-DR system; Bio-Rad Laboratories, Hercules, CA, USA) as previously described by McDougal et al. [14]. The results indicated that the isolates obtained sequentially in this case were derived from the same origin. Multilocus sequence typing (MLST) analysis was performed by sequencing seven housekeeping genes ( $\operatorname{arcC}$, aroE, $g l p F, g m k, p t a, t p i$, and $y q i L)$ based on the MLST database (http://saureus.mlst.net), as described by Enright et al. [15]. The characterization of SCCmec [16] and the detection of PVL genes [17] were performed by polymerase chain reaction as described previously. Typing of the MRSA isolates revealed that they belonged to ST72 (1-4-1-8-4-4-3), carried SCCmec type IV, and were negative for PVL.

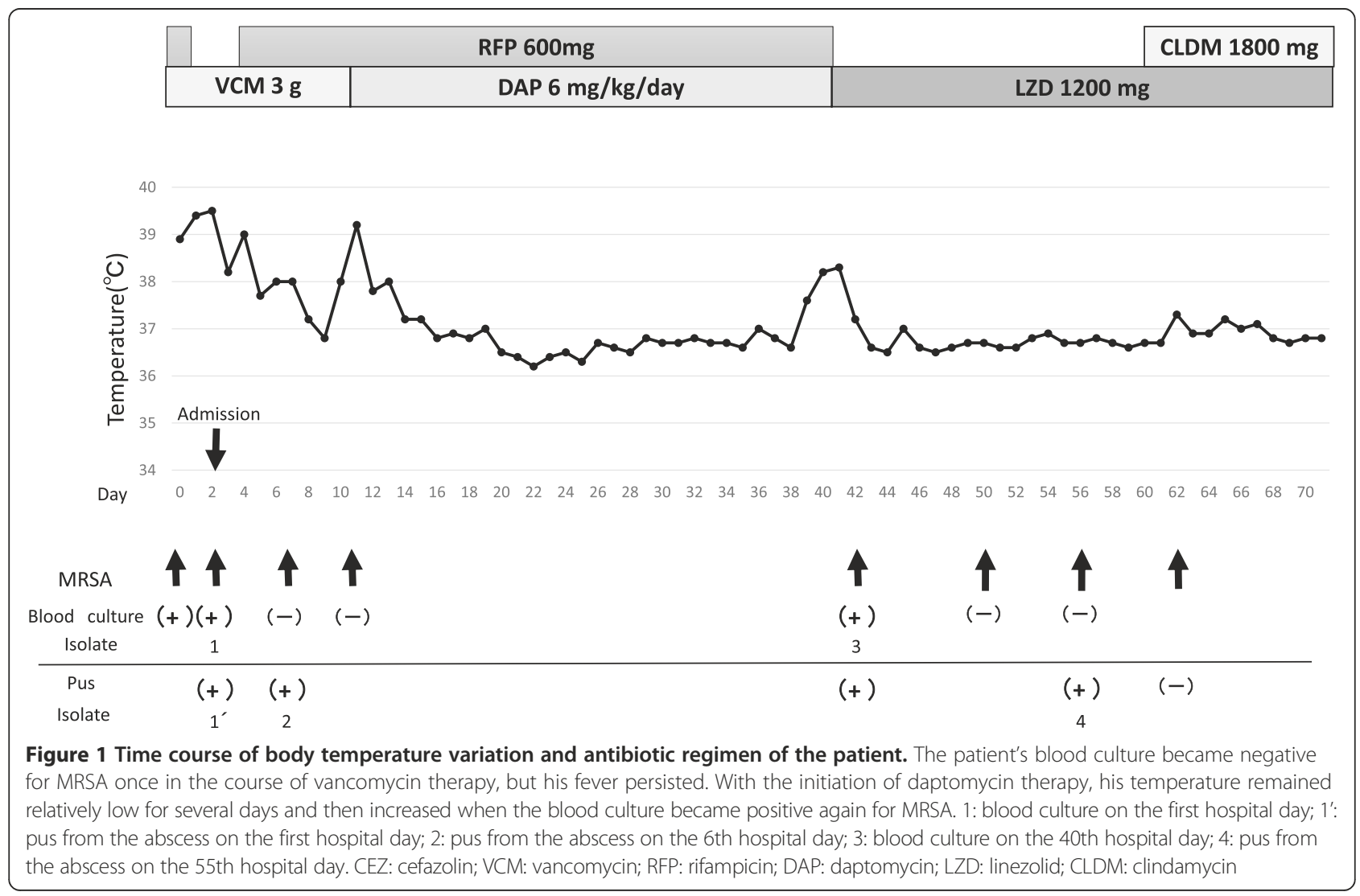


Table 2 Susceptibility of MRSA to daptomycin as analyzed by clinical laboratory testing

\begin{tabular}{|c|c|c|c|c|c|}
\hline \multirow[t]{2}{*}{ Method } & \multicolumn{5}{|c|}{ Daptomycin MIC ( $\mu \mathrm{g} / \mathrm{ml})$ [interpretation] } \\
\hline & Isolate 1 & Isolate 1' & Isolate 2 & Isolate 3 & Isolate 4 \\
\hline MicroScan (Siemens, Tokyo, Japan) & $\leq 0.5[\mathrm{~S}]$ & $\leq 0.5[\mathrm{~S}]$ & $\leq 0.5[S]$ & $>1$ [NS] & $>1[\mathrm{NS}]$ \\
\hline Frozen plate (Eiken, Tokyo, Japan) & $0.5[S]$ & $0.5[S]$ & $0.25[\mathrm{~S}]$ & $1[S]$ & 1.5 [NS] \\
\hline Etest $^{\oplus}$ (bioMérieux, Marcy-l'Étoile, France) & $0.125[S]$ & $0.125[\mathrm{~S}]$ & $0.125[S]$ & $1[S]$ & 1.5 [NS] \\
\hline
\end{tabular}

Isolate 1: blood culture on the first hospital day; Isolate1': pus from the abscess on the first hospital day; Isolate 2: pus from the abscess on the sixth hospital day; Isolate 3: blood culture on the 40th hospital day; Isolate 4: pus from the abscess on the 55th hospital day. S: Susceptible; NS: Nonsusceptible.

\section{Discussion}

The antimicrobial susceptibility rates of 25 different ST72 isolates in Korea were previously reported as follows: erythromycin (4\%), clindamycin (4\%), ciprofloxacin (60\%), TMP/SXT (96\%), gentamicin (72\%), rifampicin (92\%), and vancomycin (100\%) [6]. Although the ST72-MRSA-IV isolates in the present case were susceptible to most non- $\beta$-lactam agents (Table 1 ), they developed reduced susceptibility to three key drugs, namely vancomycin, daptomycin, and rifampicin.

The possible risk factors for the development of daptomycin nonsusceptible strains in our case, as in common MRSA strains, included the following: the presence of an intractable infectious disease (prosthetic graft infection of the aortic arch), a delay in the performance of necessary surgical care [18], previous exposure to vancomycin or a vancomycin $\mathrm{MIC}$ of $\geq 2 \mu \mathrm{g} / \mathrm{ml}$ [19], treatment with insufficient doses of daptomycin [20], and prolonged use of daptomycin [21]. Additionally, some reports have stated that VISA exhibits reduced susceptibility to daptomycin [22,23].

Another possible factor was the presence of resistance to rifampicin, which was added to allow for vancomycin penetration into the biofilm [24]. The combined use of vancomycin and rifampicin is reportedly a potential risk factor in the treatment of MRSA [25]. Cui et al. confirmed that rрoB (RNA polymerase subunit $\beta$ ) mutation, known to be associated with rifampicin resistance [26], conferred dual heteroresistance to daptomycin and vancomycin in S. aureus and exhibited a thickened cell wall and reduction of the negative charge on the cell surface [27]. The mechanism of resistance to daptomycin remains unclear. However, considering that the present case involved a daptomycin-nonsusceptible VISA strain with rifampicin resistance, it is quite possible that the $r p o B$ mutation, led by the combined treatment of vancomycin and rifampicin, may have contributed to the development of resistance.

Among the above-mentioned risk factors, our case involved those that could have been avoided or decreased by alternative therapy. An alternative approach to decreasing these risk factors could have been the administration of high-dose daptomycin upon the diagnosis of an intractable MRSA infection. Daptomycin exhibits rapid and concentration-dependent bactericidal activity, which translates into an increased rate of killing against most drug- susceptible strains and improved activity even against some nonsusceptible strains $[20,28,29]$. Rose et al. stated that high-dose daptomycin at $10 \mathrm{mg} / \mathrm{kg} /$ day was likely to prevent the emergence of increased daptomycin MICs $[20,29]$. The safety and efficacy of daptomycin at 8 to $12 \mathrm{mg} / \mathrm{kg} /$ day for the treatment of complicated bacteremia have also been reported [28]. Additionally, early use of daptomycin at higher doses was proven to be effective when the initial vancomycin MIC showed susceptibility at $>1 \mu \mathrm{g} / \mathrm{ml}$ [30]. Although the Infectious Diseases Society of America recommends an alternative to vancomycin for isolates with a vancomycin MIC of $\geq 2 \mu \mathrm{g} / \mathrm{ml}$, we recommend an early treatment switch in patients with intractable disease with a vancomycin susceptibility level of $>1 \mu \mathrm{g} / \mathrm{ml}$.

\section{Conclusions}

We have herein reported the first case of daptomycin nonsusceptibility among clinical ST72-MRSA-IV strains, which are rarely observed in countries other than Korea. In this case, failure to implement the appropriate dose and combination of antibacterial agents might have contributed to the development of nonsusceptibility. Further efforts to understand the changing epidemiology and the risk factors for antibiotic resistance will be necessary to minimize the future emergence or spread of antibioticresistant strains.

\section{Consent}

Written informed consent was obtained from the patient for the publication of this case report and any accompanying images. A copy of the written informed consent is available for review by the Editor of this journal.

\section{Ethics statement}

This study was performed in accordance with the Helsinki Declaration. No human experimentation was performed. No ethical approval from the ethics committee of Tokyo Medical University was required for this study.

\section{Abbreviations}

MRSA: Methicillin-resistant Staphylococcus aureus; CA: Community-acquired; SCCmec: Staphylococcal cassette chromosome mec; ST72-MRSA-IV: Sequence type 72 MRSA SCCmec type IV; HA: Healthcare-associated; VISA: Vancomycinintermediate Staphylococcus aureus; MIC: Minimum inhibitory concentration; CLSI: Clinical and Laboratory Standards Institute; MLST: Multilocus sequence typing; PVL: Panton-Valentine leukocidin. 


\section{Competing interests}

The authors declare that they have no competing interests.

\section{Authors' contributions}

AT attended to the patient, evaluated the case, and wrote the manuscript. IN attended to the patient, supervised the work, and drafted the manuscript. SO and TY analyzed the samples, performed the phenotypic and genotypic characterization of the MRSA strains, and drafted the manuscript. AO, SF, and YM reviewed and drafted the manuscript. TM supervised the writing of the manuscript. All authors read and approved the contents of the manuscript.

\section{Acknowledgments}

We thank K. Chiba of the Department of Microbiology, Tokyo Medical University Hospital for assisting with the microbiological analysis and providing suggestions regarding this study. We also thank Professor Jeremy David Williams of the Department of International Medical Communications of Tokyo Medical University for the editorial review of the English manuscript.

\section{Author details}

${ }^{1}$ Department of Infection Control and Prevention, Tokyo Medical University Hospital, 6-7-1 Nishishinjuku, Shinjuku-ku, Tokyo 160-0023, Japan. ${ }^{2}$ Department of Microbiology, Tokyo Medical University, 6-1-1 Nishishinjuku, Shinjuku-ku, Tokyo 160-8402, Japan. ${ }^{3}$ Department of Medical Treatment for Health Scientific Research, Bunkyo Gakuin University Graduate School, 1-19-1 Mukougaoka, Bunkyo-ku, Tokyo 113-8668, Japan. ${ }^{4}$ Department of Microbiology and Infectious Diseases, Toho University Faculty of Medicine, 5-21-16 Omorinishi, Oota-ku, Tokyo 143-8540, Japan.

Received: 17 May 2014 Accepted: 18 August 2014 Published: 23 August 2014

\section{References}

1. David MZ, Daum RS: Community-associated methicillin-resistant Staphylococcus aureus: epidemiology and clinical consequences of an emerging epidemic. Clin Microbiol Rev 2010, 23(3):616-687.

2. Naimi TS, LeDell KH, Como-Sabetti K, Borchardt SM, Boxrud DJ, Etienne J, Johnson SK, Vandenesch F, Fridkin S, O'Boyle C, Danila RN, Lynfield R: Comparison of community- and health care-associated methicillinresistant Staphylococcus aureus infection. JAMA 2003, 290(22):2976-2984.

3. Nakamura I, Yamaguchi T, Miura Y, Shimizu H, Fukushima S, Mizuno Y, Matsumoto T: Clinical aspects of infection with methicillin-resistant Staphylococcus aureus USA300 strain, generally regarded as community-acquired, in Japan. Jpn J Infect Dis 2013, 66(5):416-420.

4. Tenover FC, Goering RV: Methicillin-resistant Staphylococcus aureus strain USA300: origin and epidemiology. J Antimicrob Chemother 2009, 64(3):441-446.

5. Song JH, Hsueh PR, Chung DR, Ko KS, Kang Cl, Peck KR, Yeom JS, Kim SW, Chang HH, Kim YS, Jung SI, Son JS, So TM, Lalitha MK, Yang Y, Huang SG, Wang H, Lu Q, Carlos CC, Perera JA, Chiu CH, Liu JW, Chongthaleong A, Thamlikitkul V, Van PH: Spread of methicillin-resistant Staphylococcus aureus between the community and the hospitals in Asian countries: an ANSORP study. J Antimicrob Chemother 2011, 66(5):1061-1069.

6. Kim ES, Song JS, Lee HJ, Choe PG, Park KH, Cho JH, Park WB, Kim SH, Bang JH, Kim DM, Park KU, Shin S, Lee MS, Choi HJ, Kim NJ, Kim EC, Oh MD, Kim HB, Choe KW: A survey of community-associated methicillin-resistant Staphylococcus aureus in Korea. J Antimicrob Chemother 2007, 60(5):1108-1114.

7. Ko KS, Lim SK, Jung SC, Yoon JM, Choi JY, Song JH: Sequence type 72 meticillin-resistant Staphylococcus aureus isolates from humans, raw meat and soil in South Korea. J Med Microbiol 2011, 60(Pt 4):442-445.

8. Joo EJ, Chung DR, Ha YE, Park SY, Kim HA, Lim MH, Kim SH, Kang Cl, Lee $\mathrm{NY}$, Ko KS, Peck KR, Song JH: Clinical predictors of community-genotype ST72-methicillin-resistant Staphylococcus aureus-SCCmec type IV in patients with community-onset S. aureus infection. J Antimicrob Chemother 2012, 67(7):1755-1759.

9. Steenbergen JN, Alder J, Thorne GM, Tally FP: Daptomycin: a lipopeptide antibiotic for the treatment of serious Gram-positive infections. J Antimicrob Chemother 2005, 55(3):283-288.

10. Critchley IA, Draghi DC, Sahm DF, Thornsberry C, Jones ME, Karlowsky JA: Activity of daptomycin against susceptible and multidrug-resistant Gram-positive pathogens collected in the SECURE study (Europe) during 2000-2001. J Antimicrob Chemother 2003, 51(3):639-649.
11. Murthy $M H$, Olson ME, Wickert RW, Fey PD, Jalali Z: Daptomycin non-susceptible meticillin-resistant Staphylococcus aureus USA 300 isolate. J Med Microbiol 2008, 57(Pt 8):1036-1038.

12. Graber CJ, Wong MK, Carleton HA, Perdreau-Remington F, Haller BL, Chambers HF: Intermediate vancomycin susceptibility in a community-associated MRSA clone. Emerg Infect Dis 2007, 13(3):491-493.

13. Chung DR, Baek JY, Kim HA, Lim MH, Kim SH, Ko KS, Kang Cl, Peck KR, Lee NY, Song $\mathrm{JH}$ : First report of vancomycin-intermediate resistance in sequence type 72 community genotype methicillin-resistant Staphylococcus aureus. J Clin Microbiol 2012, 50(7):2513-2514.

14. McDougal LK, Steward CD, Killgore GE, Chaitram JM, McAllister SK, Tenover FC: Pulsed-field gel electrophoresis typing of oxacillin-resistant Staphylococcus aureus isolates from the United States: establishing a national database. J Clin Microbiol 2003, 41(11):5113-5120.

15. Enright MC, Day NP, Davies CE, Peacock SJ, Spratt BG: Multilocus sequence typing for characterization of methicillin-resistant and methicillin-susceptible clones of Staphylococcus aureus. J Clin Microbiol 2000, 38(3):1008-1015.

16. Kondo Y, Ito T, Ma XX, Watanabe S, Kreiswirth BN, Etienne J, Hiramatsu K: Combination of multiplex PCRs for staphylococcal cassette chromosome mec type assignment: rapid identification system for mec, ccr, and major differences in junkyard regions. Antimicrob Agents Chemother 2007, 51(1):264-274

17. Lina G, Piemont Y, Godail-Gamot F, Bes M, Peter MO, Gauduchon V, Vandenesch F, Etienne J: Involvement of Panton-Valentine leukocidinproducing Staphylococcus aureus in primary skin infections and pneumonia. Clin Infect Dis 1999, 29(5):1128-1132.

18. Fowler VG Jr, Boucher HW, Corey GR, Abrutyn E, Karchmer AW, Rupp ME, Levine DP, Chambers HF, Tally FP, Vigliani GA, Cabell CH, Link AS, DeMeyer I, Filler SG, Zervos M, Cook P, Parsonnet J, Bernstein JM, Price CS, Forrest GN, Fatkenheuer G, Gareca M, Rehm SJ, Brodt HR, Tice A, Cosgrove SE: Daptomycin versus standard therapy for bacteremia and endocarditis caused by Staphylococcus aureus. N Engl J Med 2006, 355(7):653-665.

19. Moise PA, Smyth DS, El-Fawal N, Robinson DA, Holden PN, Forrest A, Sakoulas G: Microbiological effects of prior vancomycin use in patients with methicillin-resistant Staphylococcus aureus bacteraemia. J Antimicrob Chemother 2008, 61(1):85-90.

20. Rose WE, Rybak MJ, Kaatz GW: Evaluation of daptomycin treatment of Staphylococcus aureus bacterial endocarditis: an in vitro and in vivo simulation using historical and current dosing strategies. J Antimicrob Chemother 2007, 60(2):334-340.

21. Mangili A, Bica I, Snydman DR, Hamer DH: Daptomycin-resistant, methicillin-resistant Staphylococcus aureus bacteremia. Clin Infect Dis 2005, 40(7):1058-1060.

22. Cui L, Tominaga E, Neoh HM, Hiramatsu K: Correlation between Reduced Daptomycin Susceptibility and Vancomycin Resistance in VancomycinIntermediate Staphylococcus aureus. Antimicrob Agents Chemother 2006, 50(3):1079-1082.

23. Kelley PG, Gao W, Ward PB, Howden BP: Daptomycin non-susceptibility in vancomycin-intermediate Staphylococcus aureus (VISA) and heterogeneous-VISA (hVISA): implications for therapy after vancomycin treatment failure. J Antimicrob Chemother 2011, 66(5):1057-1060.

24. Saginur R, Stdenis M, Ferris W, Aaron SD, Chan F, Lee C, Ramotar K: Multiple combination bactericidal testing of staphylococcal biofilms from implantassociated infections. Antimicrob Agents Chemother 2006, 50(1):55-61.

25. Matsuo M, Hishinuma T, Katayama Y, Cui L, Kapi M, Hiramatsu K: Mutation of RNA polymerase beta subunit (rpoB) promotes hVISA-to-VISA phenotypic conversion of strain Mu3. Antimicrob Agents Chemother 2011, 55(9):4188-4195.

26. Aubry-Damon H, Soussy CJ, Courvalin P: Characterization of mutations in the rpoB gene that confer rifampin resistance in Staphylococcus aureus. Antimicrob Agents Chemother 1998, 42(10):2590-2594.

27. Cui L, Isii T, Fukuda M, Ochiai T, Neoh HM, Camargo IL, Watanabe Y, Shoji M, Hishinuma T, Hiramatsu K: An RpoB mutation confers dual heteroresistance to daptomycin and vancomycin in Staphylococcus aureus. Antimicrob Agents Chemother 2010, 54(12):5222-5233.

28. Benvenuto M, Benziger DP, Yankelev S, Vigliani G: Pharmacokinetics and tolerability of daptomycin at doses up to 12 milligrams per kilogram of body weight once daily in healthy volunteers. Antimicrob Agents Chemother 2006, 50(10):3245-3249.

29. Rose WE, Leonard SN, Rybak MJ: Evaluation of daptomycin pharmacodynamics and resistance at various dosage regimens against Staphylococcus aureus 
isolates with reduced susceptibilities to daptomycin in an in vitro pharmacodynamic model with simulated endocardial vegetations. Antimicrob Agents Chemother 2008, 52(9):3061-3067.

30. Murray KP, Zhao JJ, Davis SL, Kullar R, Kaye KS, Lephart P, Rybak MJ: Early use of daptomycin versus vancomycin for methicillin-resistant Staphylococcus aureus bacteremia with vancomycin minimum inhibitory concentration $>1$ mg/L: a matched cohort study. Clin Infect Dis 2013, 56(11):1562-1569.

doi:10.1186/1471-2334-14-459

Cite this article as: Tsukimori et al:: First case report of vancomycinintermediate sequence type 72 Staphylococcus aureus with nonsusceptibility to daptomycin. BMC Infectious Diseases 2014 14:459.

\section{Submit your next manuscript to BioMed Central and take full advantage of:}

- Convenient online submission

- Thorough peer review

- No space constraints or color figure charges

- Immediate publication on acceptance

- Inclusion in PubMed, CAS, Scopus and Google Scholar

- Research which is freely available for redistribution 